\title{
ESTUDIO SEROEPIDEMIOLOGICO DE BRUCELOSIS EN ALUMNOS DE MEDICINA VETERINARIA EN LOS AÑOS 1996 Y 1997
}

\author{
TRABATTONI, E. ${ }^{1}$, LAVARONI, O. ${ }^{1}$, \\ Delgado, a. ${ }^{2}$, Vera, e. ${ }^{1}$ \& Garcia, N. $^{3}$
}

\begin{abstract}
RESUMEN
Durante los meses de julio de 1996 a julio de 1997 se analizaron 359 sueros pertenecientes a alumnos estudiantes de la carrera de Medicina Veterinaria de la Facultad de Agronomía y Veterinaria de Esperanza. A los individuos muestreados se les realizó una encuesta y a sus sueros se los sometió a las pruebas en tubo de Wright, 2-Mercaptoetanol y Fijación de Complemento para la detección de anticuerpos brucélicos. Como resultado, reaccionaron en forma positiva a Wright 15 (prevalencia 4,17\%) sueros, de éstos, tres fueron positivos a 2-Mercaptoetanol y uno, a Fijación de complemento.
\end{abstract}

Palabras clave: brucelosis, estudiantes, encuesta, veterinaria.

\section{SUMMARY}

\section{Seroepideniological study of brucellosis in students of Veterinary Medicine in 1996 - 1997.}

From July 1996 to July 1997, a survey was carried out on 359 students from the Faculty of Agronomy and Veterinary, Esperanza. Serological samples were tested for brucellosis by means of wright test (WT), 2-Mercaptoetanol (2-ME) and complement fixation (CF). A personal interview using an structured questionnaire was also carried out. Fifteen (4.17\%) serum samples were positive to WT, three to 2-ME and one to CF.

Key words: brucelosis, student, veterinary, questionnaire.

\footnotetext{
1.- Cátedra de Inmunología. Facultad de Ciencias Veterinarias. Universidad Nacional del Litoral. Kreder 2805. (3080) Esperanza, provincia de Santa Fe. Tel: (03496) 420639.

2.- Cátedra de Bacteriología y Micología. Dpto. de Patología. Facultad de Ciencias Veterinarias,

Universidad Nacional del Litoral.

3.- Bioquímico. Actividad privada.

Manuscrito recibido el 15 de febrero de 2001 y aceptado para su publicación el 5 de agosto de 2002.
} 